\title{
Impact of Obesity and Underweight on Surgical Outcome of Lumbar Disc Herniation
}

\author{
Farzad Omidi-Kashani, ${ }^{1}$ Ebrahim Ghayem Hasankhani, ${ }^{1}$ Ehsan Rafeemanesh, ${ }^{2}$ \\ Parham Seyf, ${ }^{3}$ Hassan Attarchi, ${ }^{3}$ Mohammad Dawood Rahimi, ${ }^{4}$ and Reza Khanzadeh ${ }^{5}$ \\ ${ }^{1}$ Orthopedic Department, Orthopedic and Trauma Research Center, Imam Reza Hospital, Mashhad University of Medical Sciences, \\ Mashhad 3316-913791, Iran \\ ${ }^{2}$ Faculty of Medicine, Mashhad University of Medical Sciences, Mashhad 3316-913791, Iran \\ ${ }^{3}$ Imam Reza Hospital, Mashhad University of Medical Sciences, Mashhad 3316-913791, Iran \\ ${ }^{4}$ Orthopaedic and Trauma Research Center, Mashhad University of Medical Sciences, Mashhad 3316-913791, Iran \\ ${ }^{5}$ College of Physical Education and Sport Sciences, Ferdowsi University of Mashhad, Mashhad 91779-48974, Iran
}

Correspondence should be addressed to Farzad Omidi-Kashani; omidif@mums.ac.ir

Received 16 November 2013; Accepted 15 December 2013; Published 9 January 2014

Academic Editors: H.-Y. Lee and T. Rekand

Copyright (C) 2014 Farzad Omidi-Kashani et al. This is an open access article distributed under the Creative Commons Attribution License, which permits unrestricted use, distribution, and reproduction in any medium, provided the original work is properly cited.

Background. The relationship between underweight and lumbar spine surgery is still unknown. Aim. To evaluate the effect of underweight versus obesity based on surgical outcome of lumbar disc herniation. Material and Method. In this retrospective study, we evaluated 206 patients (112 male and 94 female) with a mean age of $37.5 \pm 3.1$ years old (ranged 20-72) who have been surgically treated due to the refractory simple primary L4-L5 disc herniation. We followed them up for a mean period of $42.4 \pm 7.2$ months (ranged 24-57). We used Body Mass Index (BMI), Oswestry Disability Index (ODI), and Visual Analogue Scale (VAS) for categorization, disability, and pain assessment, respectively. We used Wilcoxon and Mann-Whitney $U$ tests for statistics. Results. Surgical discectomy in all weight groups was associated with significant improvement in pain and disability, but intergroup comparison showed these improvements in both underweight and obese groups and they were significantly lower than in normal weight group. Excellent and good satisfaction rate was also somewhat lower in both these ends of weight spectrum, but statistically insignificant. Conclusion. Both obesity and underweight may have adverse prognostic influences on the surgical outcome of lumbar disc herniation, although their impact on subjective satisfaction rate seems to be insignificant.

\section{Introduction}

Obesity with its increased stress on the lumbar spine has a known adverse effect on lumbar intervertebral discs. The relationship between obesity and low back pain (LBP) has been repeatedly discussed previously. Numerous authors emphasized the unfavorable effects of obesity on the spinal column including back pain, facet arthrosis, and degenerative disc disease [1-11]. Albeit, it is worth noting that this relationship is not accepted by all authors [12]. Obesity has also been accused of an increased incidence of postoperative spinal complications, but in appropriately indicated patients, it is certainly associate with satisfactory outcomes [13-16].

Therefore, it is nearly proven that obesity has several adverse effects on the lumbar spine but does this mean that underweight has a protective effect on it? Is underweight associated with better lumbar spinal surgical outcomes? There is still little investigation has been performed to evaluate a possible relationship between underweight and the results of lumbar surgeries. In this study we aimed to evaluate the effect of underweight versus obesity on the surgical outcome of the patients with symptomatic lumbar disc herniation who have undergone operative treatment.

\section{Materials and Method}

In this retrospective study, after local institutional review board approval (code 920590), we evaluated the patients who have been treated due to the refractory simple lumbar disc 
TABLE 1: Demographic data of our treated patients.

\begin{tabular}{|c|c|c|c|c|c|}
\hline \multirow{2}{*}{ Group } & \multirow{2}{*}{ Number } & \multicolumn{2}{|c|}{ Sex } & \multirow{2}{*}{ Mean age \pm SD } & \multirow{2}{*}{ Mean BMI \pm SD } \\
\hline & & Male & Female & & \\
\hline Underweight & 24 & $11(45.8 \%)$ & $13(54.2 \%)$ & $40.2 \pm 3.4$ & $17.7 \pm 0.6$ \\
\hline Normal & 81 & $50(61.7 \%)$ & $31(38.3 \%)$ & $36.3 \pm 3.2$ & $22.1 \pm 1.7$ \\
\hline Overweight & 56 & $27(48.2 \%)$ & $29(51.8)$ & $37.5 \pm 2.7$ & $27.4 \pm 0.9$ \\
\hline Obese & 45 & $24(53.3 \%)$ & $21(46.7 \%)$ & $38.3 \pm 1.4$ & $32.2 \pm 0.8$ \\
\hline
\end{tabular}

herniation in our orthopedic department from August 2008 to June 2011. Our inclusion criteria comprised the patients with single level lower lumbar disc herniation, aged $>20$ years, refractory to the aggressive medical treatment of more than 6 weeks, and the patients with progressive neurologic deficit. The patients with unstable underlying lumbar spine (associate with spondylolysis or spondylolisthesis), nondiscogenic sciatica, cauda equina syndrome, associated stenosis (other than intervertebral disc pathology), and a follow-up period of less than two years were excluded. To avoid distortion of the results, only the patients with L4-L5 disc herniation were enrolled.

We used preoperative Body Mass Index (BMI) for categorization in our patient's population. It is calculated by dividing weight (kilogram) by the square of the height (meter). In accordance with the World Health Organization (WHO) classification, adults are classified into four BMI groups: underweight $(<18.5)$, normal (18.5-24.99), overweight (2529.99), and obese (>30) [17].

The surgical technique throughout these years was the same and performed by the senior author (FOK) with the similar manner and according to the standard microlumbar discectomy [18, 19]. Pre- and postoperatively at the last follow-up visit, we assessed the patients with two questionnaires; Oswestry Disability Index (ODI) version 2.1 and 0 to 10 Visual Analogue Scale (VAS) [20-22]. In the latter questionnaire, we asked the patients to rate their severity of pain from 0 to 10 on a marked sheet. In terms of ODI and VAS improvement, the revision cases were excluded, although these cases accounted for comparison between the weight groups. At the last visit, we also measured revision rate and the patient's satisfaction from surgery with North American Spine Society Low Back Outcome Instrument [23]. The latter comprised a four questions form about the patient's satisfaction rate from the surgical management and scored as (1) excellent when the surgery fulfilled her/his expectations, (2) good when the patient did not get better as much as he/she had expected, but again with the same disease, he/she would choose the same surgical procedure for the same result, (3) fair when surgery helped but he/she would not endure the same procedure for the same result, and (4) poor when the patient's status has not changed or he/she is even worse than he/she was before.

2.1. Statistics. Wilcoxon test was used to compare pre- and postoperative VAS and ODI in each group. We used MannWhitney $U$ test to compare the mean changes of indices between the groups. Statistical Package for Social Sciences
(SPSS) version 11.5 for Windows (SPSS Inc., Chicago, IL, USA) was used to perform statistical analysis and we considered $P<0.05$ as statistically significant.

\section{Results}

After excluding 16 cases (nine patients due to revision surgeries and seven due to the lack of follow-up period), we ultimately could evaluate 206 Patients; 112 (54.4\%) male and $94(45.6 \%)$ female with a mean age of $37.5 \pm 3.1$ years old (ranged 20 to 72). Demographic data of the different weight groups are presented in Table 1 . The mean follow-up period was $42.4 \pm 7.2$ (ranged; $24-57$ months). The mean follow-up periods between the groups were not significantly different. The means preoperative, last postoperative, and improvement in VAS and ODI are also depicted in Table 2.

As expected, surgical discectomy in all weight groups were associated with significant improvement in pain and disability (Table 2), but when comparing weight groups together, the results were somewhat different (Table 3 ).

Overall Patient satisfaction rate in our patients (Table 4) comprised excellent in 169 patients (82.1\%), good $21(10.2 \%)$, fair 11 (5.3\%), and poor 5 (2.4\%). Although, the mean overall rate of excellent and good satisfaction rate in underweight and obese patients were somewhat lower than normal or overweight, the differences among the groups were not significant statistically. The recurrence and revision rate among weight groups are also shown in Table 4 . We could not find a significant difference between these two indices in the various weight groups.

\section{Discussion}

As life becoming more industrialized, the incidence of malnutrition (underweight and obesity) is also increasing. Our results showed that not only obesity but also underweight is probably associated with decreased surgical outcomes of lumbar discectomy. It seems that thinness probably due to less muscular support or other unknown reasons is a less known poor prognostic factor in surgery of lumbar disc herniation and according to our knowledge; this issue has not been previously evaluated.

A review of the literature clearly demonstrates that obesity in various kinds of orthopaedic issues is associated with more serious consequences. Although surgical site infection did not occur in any of our patients, it is frequently reported to be higher in obese patients and this may be due to several factors including longer surgical time, greater surgical 
TAble 2: Mean Pre- and postoperative (last visit) pain and disability.

\begin{tabular}{|c|c|c|c|c|c|}
\hline Group & Preoperative & Last Visit & $z$ & $P$ value & Mean Improvement \\
\hline \multicolumn{6}{|l|}{ Underweight } \\
\hline VAS leg & $8.3 \pm 1.22$ & $2.3 \pm 1.4$ & 3.2 & 0.001 & $5.7 \pm 2.2$ \\
\hline VAS lumbar & $7.1 \pm 1.3$ & $2.6 \pm 1.9$ & 3.24 & 0.001 & $5.2 \pm 1.7$ \\
\hline ODI & $63.1 \pm 1.1$ & $25.5 \pm 1.9$ & 3.19 & 0.001 & $37.5 \pm 1.5$ \\
\hline \multicolumn{6}{|l|}{ Normal Weight } \\
\hline VAS leg & $8.4 \pm 1.4$ & $1.5 \pm 0.7$ & 3.44 & 0.001 & $7.9 \pm 1.1$ \\
\hline VAS lumbar & $8.2 \pm 1.4$ & $1.3 \pm 0.9$ & 3.45 & 0.001 & $7.5 \pm 1.3$ \\
\hline ODI & $67.6 \pm 1.5$ & $12.3 \pm 1.3$ & 3.41 & 0.001 & $55.3 \pm 1.5$ \\
\hline \multicolumn{6}{|l|}{ Over Weight } \\
\hline VAS leg & $8.1 \pm 1.7$ & $1.4 \pm 2.2$ & 5.1 & 0.001 & $6.4 \pm 2.4$ \\
\hline VAS lumbar & $7.5 \pm 1.7$ & $1.6 \pm 2.1$ & 5.1 & 0.001 & $5.8 \pm 2.6$ \\
\hline ODI & $60.5 \pm 1.2$ & $16.8 \pm 2.2$ & 5 & 0.001 & $49.1 \pm 1.8$ \\
\hline \multicolumn{6}{|l|}{ Obese } \\
\hline VAS leg & $8.0 \pm 1.6$ & $2.0 \pm 2.7$ & 3.9 & 0.001 & $6.1 \pm 2.7$ \\
\hline VAS lumbar & $7.0 \pm 2.6$ & $1.9 \pm 2.3$ & 3.8 & 0.001 & $5.1 \pm 3.2$ \\
\hline ODI & $53.9 \pm 1.9$ & $16.3 \pm 1.9$ & 4 & 0.001 & $38.7 \pm 2.5$ \\
\hline
\end{tabular}

TABLE 3: Intergroupcomparisonin terms of pain and disability improvement.

\begin{tabular}{lccc}
\hline Group & Improvement & $z$ & $P$ value \\
\hline Underweight & VAS leg & 0.74 & 0.45 \\
Obese & VAS lumbar & 0.46 & 0.64 \\
& ODI & 1.4 & 0.88 \\
& VAS leg & 1.1 & 0.25 \\
Overweight & VAS lumbar & 1.7 & 0.08 \\
& ODI & 1.5 & 0.13 \\
& VAS leg & 2.8 & $0.005^{*}$ \\
Normal & VAS lumbar & 3.4 & $0.001^{*}$ \\
& ODI & 2.47 & $0.013^{*}$ \\
Obese & & & \\
\multirow{4}{*}{ Overweight } & VAS leg & 0.44 & 0.65 \\
& VAS lumbar & 0.25 & 0.72 \\
& ODI & 1.49 & 0.13 \\
Normal & VAS leg & 2.1 & $0.03^{*}$ \\
& VAS lumbar & 2.34 & $0.01^{*}$ \\
Overweight & ODI & 2.03 & $0.04^{*}$ \\
& & & \\
Normal & VAS leg & 1.84 & 0.06 \\
& VAS lumbar & 2.62 & 0.09 \\
& ODI & 0.95 & 0.34 \\
\hline
\end{tabular}

* Statistically significant.

dissection through the poorly vascularized fat, nutritional deprivation of essential elements, and inadequate adjustment of the antibiotic dosage based on patient's weight [24-27].

Some authors evaluated the association of obesity and spinal surgical outcome. Gepstein et al. in 2004 conducted a retrospective study on 298 elderly patients ( $<65$ years old) and evaluated the effect of various amount of BMI on surgical outcome of simple lumbar discectomy [28]. They observed that all groups of patients including obese and emaciated had satisfactory surgical outcome associated with improvement in pain and activity of daily living. They suggested that it's not fair to deprive obese appropriately indicated patients from the surgery only due to the weight. Rihn and coauthors in another study evaluated the obesity impact on treatment outcomes for lumbar spinal stenosis and degenerative spondylolisthesis [29]. In this study, obese patients were compared with nonobese $(\mathrm{BMI}<30)$ and followed-up to four years. They observed that obesity does not have an effect on the surgical outcome of spinal stenosis, but in the patients with LDS, infection and reoperation rates are higher and improvement in physical function score of SF-36 is lower in obese patients. In obese patients with spinal stenosis or LDS, surgery is more efficient than conservative treatment. In another extensive study of 2633 patients from the Swedish Spine Register that recently was conducted by Knutsson et al., the association between BMI and surgical outcome of lumbar spinal stenosis was assessed [30]. The patients were followedup for more than two years. The outcomes were measured by the ODI and the EuroQol Group Index (EQ-5D). The results of this study also confirmed that although the obese patients obtained considerable improvement after surgical intervention for lumbar SS, obesity was linked to higher degree of dissatisfaction and inferior surgical outcomes.

Rihn et al. also in a similar research analyzed the impact of obesity on the treatment (conservative or surgical) results of symptomatic lumbar disc herniation [31]. Similarly, in this study 336 obese patients (BMI $\geq 30$ ) were compared with 854 nonobese and followed-up to four years. The patients were assessed by Short Form (SF-36) and ODI questionnaires. The results showed that obese cases are more expected to be operated for lumbar disc herniation and also the operation 
TABLE 4: Recurrence and revision rate among difference weight groups.

\begin{tabular}{|c|c|c|c|c|c|c|}
\hline \multirow{2}{*}{ Group } & \multicolumn{4}{|c|}{ Patient satisfaction } & \multirow{2}{*}{ Recurrence $^{*}(\%)$} & \multirow{2}{*}{ Revision $^{\#}(\%)$} \\
\hline & Excellent (\%) & Good (\%) & Fair (\%) & Poor $(\%)$ & & \\
\hline Underweight & $18(75)$ & $3(12.5)$ & $2(8.3)$ & $1(4.2)$ & $3(12.5)$ & $1(4.2)$ \\
\hline Normal & $69(85.2)$ & $7(8.6)$ & $3(3.7)$ & $2(2.5)$ & $7(8.6)$ & $3(3.7)$ \\
\hline Overweight & $45(80.3)$ & $7(12.5)$ & $3(5.4)$ & $1(1.8)$ & $6(10.7)$ & $2(3.6)$ \\
\hline Obese & $37(82.2)$ & $4(8.9)$ & $3(6.7)$ & $1(2.2)$ & 7 (15.6) & $3(6.7)$ \\
\hline
\end{tabular}

${ }^{*}$ Re-herniation: symptomatic recurrence of lumbar disc herniation.

\# Re-operation: revision surgery due to refractory recurrence.

in these patients are associated with more operative time, bleeding, and length of hospital stay. They finally concluded that although in both groups, the benefits of surgical treatment were greater than conservative treatment; the results of treatment (either surgical or nonsurgical) are lower in obese patients.

Minimally invasive surgery is frequently proposed as the preferred spinal procedure in obese patients. Park et al. also evaluated 77 patients with various amount of BMI who are surgically treated with minimally invasive lumbar spine surgery [32]. These authors aimed to study the relationship between obesity and complications of MIS surgeries (including simple discectomy and/or fusion surgeries). They could not find any increased risk of perioperative complications in obese patients undergoing minimally invasive surgeries. In a similar study, Cole and Jackson also evaluated the surgical outcome of microlumbar discectomy in 32 obese patients [33]. They reported a complication and revision rate of $12.5 \%$ and $9.4 \%$, respectively and recommended this type of surgery as the preferred treatment method in obese patients to reduce the incision length and infectious complications.

A direct relationship between obesity and recurrent lumbar disc herniation has been previously suggested. In a retrospective cohort study, Meredith studied 75 patients with one or two level lumbar discectomy and followed them up for more than six months in term of recurrent lumbar disc herniation [34]. They had defined the recurrent disc herniation as a reherniation at the same level and side. They reported a recurrence rate of $10.7 \%$ and showed that the possibility of postoperative recurrent herniation and reoperation were 12 and 30 times higher in obese relative to nonobese patients, respectively. In their study, age, gender, smoking, and occupation had no significant association with the recurrence incidence. These authors finally recommended that surgeons should inform the obese patients preoperatively from this increased risk. In contradictory to this, in an extensive study conducted by Rihn et al. [31], the difference was not significant. In comparing these two studies, the number of cases studied in the latter is much higher and therefore it's more likely to be consistent with the social reality. In obese patients, it's also observed that the possibility of cauda equina syndrome due to lumbar disc herniation is much greater relative to other patients [35]. We did not evaluated this in our patients.

Our research, although presented a new possible poor prognostic factor in surgical outcome of lumbar disc herniation, it has some important flaws. It had a retrospective design and inevitably the disadvantages of this type of researches also apply to our study. Although the mean follow-up period in our study suffices to present in scientific journals, longer time evaluation certainly would increase the value of this. In the future, for better evaluation and stronger comment about the impact of underweight on surgical outcome of lumbar disc herniation, a randomized controlled trial study on a larger number of patients with more follow-up period is highly proposed. In conclusion, we found that not only obesity but also underweight may have a poor prognostic influence on the surgical outcome of lumbar discectomy, although their impact on subjective satisfaction rate seems to be insignificant. This conclusion in fact may confirm an old adage that says the middle one is the best.

\section{Conflict of Interests}

The authors declares that there is no conflict of interests.

\section{Acknowledgments}

The authors would like to thank Student Research Committee, Faculty of Medicine, Mashhad University of Medical Sciences, for its financial support.

\section{References}

[1] Centers for Disease Control and Prevention, 2011, http://www.cdc.gov/minorityhealth/reports/CHDIR11 /FactSheet.pdf.

[2] K. M. Flegal, B. I. Graubard, D. F. Williamson, and M. H. Gail, "Excess deaths associated with underweight, overweight, and obesity," Journal of the American Medical Association, vol. 293, no. 15, pp. 1861-1867, 2005.

[3] World Health Organization, "Obesity and overweight: fact sheet," 2011, http://www.who.int/mediacentre/factsheets/fs311/ en/.

[4] E. A. Finkelstein, J. G. Trogdon, J. W. Cohen, and W. Dietz, "Annual medical spending attributable to obesity: payer-and service-specific estimates," Health Affairs, vol. 28, no. 5, pp. w822-w831, 2009.

[5] O. M. Böstman, "Prevalence of obesity among patients admitted for elective orthopaedic surgery," International Journal of Obesity and Related Metabolic Disorders, vol. 18, no. 10, pp. 709-713, 1994.

[6] E. Yusuf, J. Bijsterbosch, P. E. Slagboom, F. R. Rosendaal, T. W. J. Huizinga, and M. Kloppenburg, "Body mass index and 
alignment and their interaction as risk factors for progression of knees with radiographic signs of osteoarthritis," Osteoarthritis and Cartilage, vol. 19, no. 9, pp. 1117-1122, 2011.

[7] J. Runhaar, B. W. Koes, S. Clockaerts, and S. M. A. BiermaZeinstra, "A systematic review on changed biomechanics of lower extremities in obese individuals: a possible role in development of osteoarthritis," Obesity Reviews, vol. 12, no. 12, pp. 1071-1082, 2011.

[8] M. Fransen, M. Woodward, R. Norton, C. Coggan, M. Dawe, and N. Sheridan, "Risk factors associated with the transition from acute to chronic occupational back pain," Spine, vol. 27, no. 1, pp. 92-98, 2002.

[9] T. Ohba, T. Saito, N. Kawasaki, S. Maekawa, and H. Haro, "Symptomatic spinal epidural lipomatosis with severe obesity at a young age," Orthopedics, vol. 34, no. 6, p. 233, 2011.

[10] L. Kalichman, A. Guermazi, L. Li, and D. J. Hunter, "Association between age, sex, BMI and CT-evaluated spinal degeneration features," Journal of Back and Musculoskeletal Rehabilitation, vol. 22, no. 4, pp. 189-195, 2009.

[11] M. S. Walid and N. Zaytseva, "History of spine surgery in older obese patients," German Medical Science, vol. 9, Article ID Doc05, 2011.

[12] Y. B. Yip, S. C. Ho, and S. G. Chan, "Tall stature, overweight and the prevalence of low back pain in Chinese middle-aged women," International Journal of Obesity, vol. 25, no. 6, pp. 887892, 2001

[13] T. G. Andreshak, H. S. An, J. Hall, and B. Stein, "Lumbar spine surgery in the obese patient," Journal of Spinal Disorders, vol. 10, no. 5, pp. 376-379, 1997.

[14] R. Gepstein, S. Shabat, Z. H. Arinzon, F. Berner, A. Catz, and F. Folman, "Does obesity affect the results of lumbar decompressive spinal surgery in the elderly?" Clinical Orthopaedics and Related Research, no. 426, pp. 138-144, 2004.

[15] J. W. Kardaun, L. R. White, and W. O. Shaffer, "Acute complications in patients with surgical treatment of lumbar herniated disc," Journal of Spinal Disorders, vol. 3, no. 1, pp. 30-38, 1990.

[16] N. Patel, B. Bagan, S. Vadera et al., "Obesity and spine surgery: relation to perioperative complications," Journal of Neurosurgery, vol. 6, no. 4, pp. 291-297, 2007.

[17] WHO Expert Consultation, "Appropriate body-mass index for Asian populations and its implications for policy and intervention strategies," The Lancet, vol. 363, no. 9403, pp. 157-163, 2004.

[18] R. W. Williams, "Microlumbar discectomy: a conservative surgical approach to the virgin herniated lumbar disc," Spine, vol. 3, no. 2, pp. 175-182, 1978.

[19] J. C. Maroon and A. A. Abla, "Microlumbar discectomy," Clinical Neurosurgery, vol. 33, pp. 407-417, 1986.

[20] J. C. T. Fairbank and P. B. Pynsent, "The oswestry disability index," Spine, vol. 25, no. 22, pp. 2940-2953, 2000.

[21] M. E. Wewers and N. K. Lowe, "A critical review of visual analogue scales in the measurement of clinical phenomena," Research in Nursing \& Health, vol. 13, no. 4, pp. 227-236, 1990.

[22] S. J. Mousavi, M. Parnianpour, H. Mehdian, A. Montazeri, and B. Mobini, "The oswestry disability index, the roland-morris disability questionnaire, and the quebec back pain disability scale: translation and validation studies of the Iranian versions," Spine, vol. 31, no. 14, pp. E454-E459, 2006.

[23] E. G. Wood III and E. N. Hanley Jr., "Lumbar disc herniation and open limited discectomy: indications, techniques, and results," Operative Techniques in Orthopaedics, vol. 1, no. 1, pp. 23-28, 1991.
[24] M. A. Olsen, J. J. Nepple, K. D. Riew et al., "Risk factors for surgical site infection following orthopaedic spinal operations," Journal of Bone and Joint Surgery A, vol. 90, no. 1, pp. 62-69, 2008.

[25] S. E. Porter, M. L. Graves, Z. Qin, and G. V. Russell, "Operative experience of pelvic fractures in the obese," Obesity Surgery, vol. 18, no. 6, pp. 702-708, 2008.

[26] A. Lübbeke, K. G. M. Moons, G. Garavaglia, and P. Hoffmeyer, "Outcomes of obese and nonobese patients undergoing revision total hip arthroplasty," Arthritis Care and Research, vol. 59, no. 5, pp. 738-745, 2008.

[27] M. M. Dowsey and P. F. M. Choong, "Early outcomes and complications following joint arthroplasty in obese patients: a review of the published reports," ANZ Journal of Surgery, vol. 78, no. 6, pp. 439-444, 2008.

[28] R. Gepstein, S. Shabat, Z. H. Arinzon, F. Berner, A. Catz, and F. Folman, "Does obesity affect the results of lumbar decompressive spinal surgery in the elderly?" Clinical Orthopaedics and Related Research, no. 426, pp. 138-144, 2004.

[29] J. A. Rihn, K. Radcliff, A. S. Hilibrand et al., "Does obesity affect outcomes of treatment for lumbar stenosis and degenerative spondylolisthesis? Analysis of the Spine Patient Outcomes Research Trial (SPORT)," Spine, vol. 37, no. 23, pp. 1933-1946, 2012.

[30] B. Knutsson, K. Michaëlsson, and B. Sandén, "Obesity is associated with inferior results after surgery for lumbar spinal stenosis: a study of 2633 patients from the Swedish spine register," Spine, vol. 38, no. 5, pp. 435-441, 2013.

[31] J. A. Rihn, A. S. Hilibrand, K. Radcliff et al., "The influence of obesity on the outcome of treatment of lumbar disc herniation: analysis of the Spine Patient Outcomes Research Trial (SPORT)," Journal of Bone and Joint Surgery A, vol. 95, no. 1, pp. 1-8, 2013.

[32] P. Park, C. Upadhyaya, H. J. L. Garton, and K. T. Foley, “The impact of minimally invasive spine surgery on perioperative complications in overweight or obese patients," Neurosurgery, vol. 62, no. 3, pp. 693-698, 2008.

[33] J. S. Cole IV and T. R. Jackson, "Minimally invasive lumbar discectomy in obese patients," Neurosurgery, vol. 61, no. 3, pp. 539-544, 2007.

[34] D. S. Meredith, R. C. Huang, J. Nguyen, and S. Lyman, "Obesity increases the risk of recurrent herniated nucleus pulposus after lumbar microdiscectomy," Spine Journal, vol. 10, no. 7, pp. 575580, 2010.

[35] M. Venkatesan, C. E. Uzoigwe, G. Perianayagam, J. R. Braybrooke, and M. L. Newey, "Is cauda equina syndrome linked with obesity?" Journal of Bone and Joint Surgery, vol. 94, no. 11, pp. 1551-1556, 2012. 

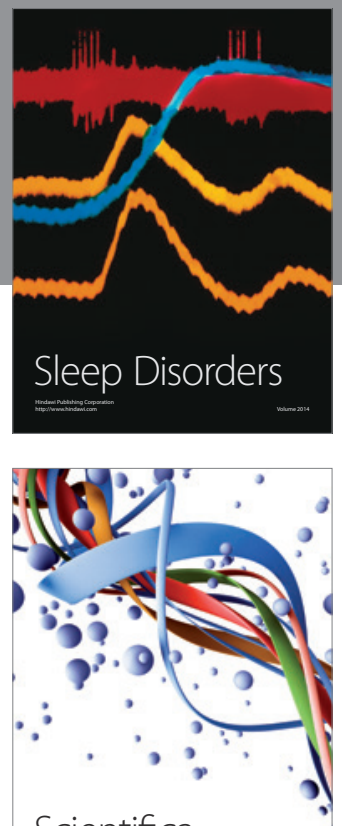

Scientifica
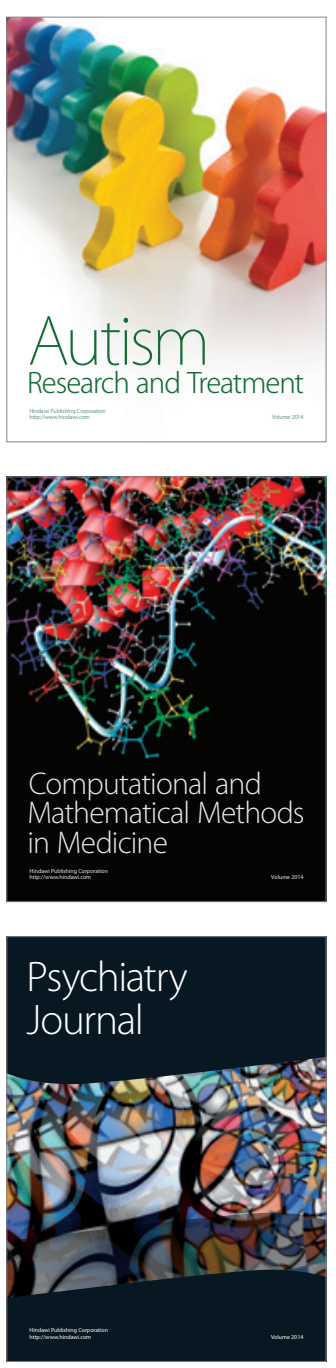
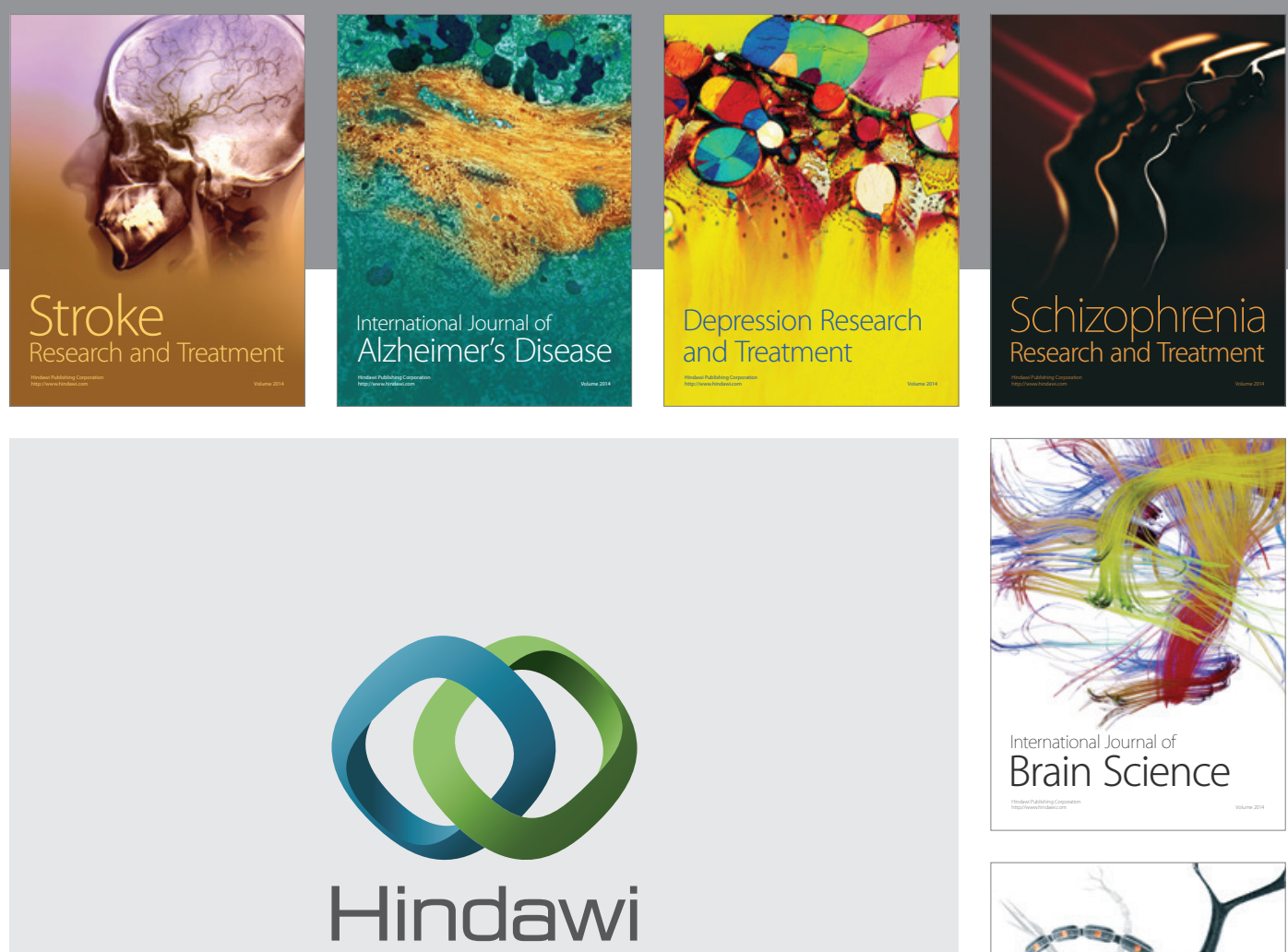

Submit your manuscripts at

http://www.hindawi.com
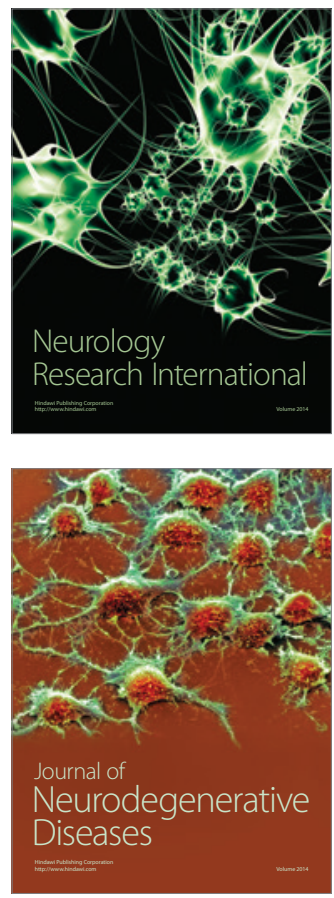

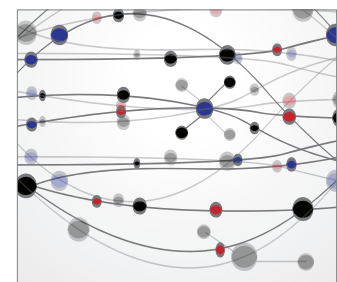

The Scientific World Journal
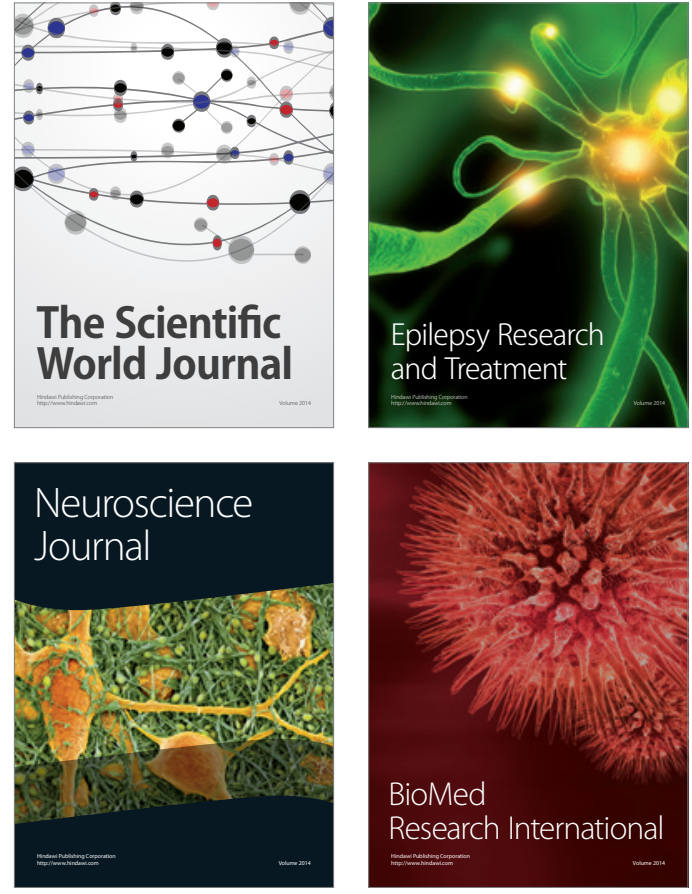

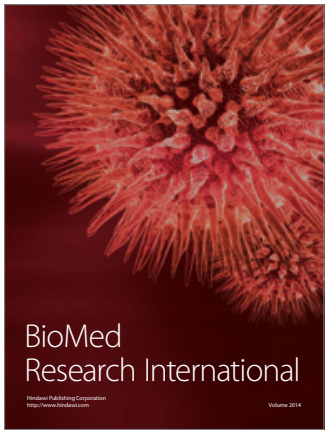

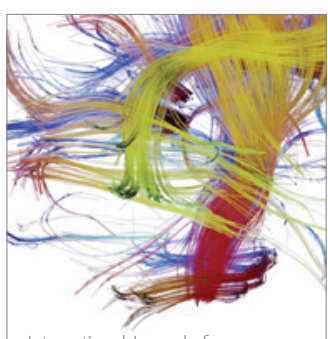

Brain Science

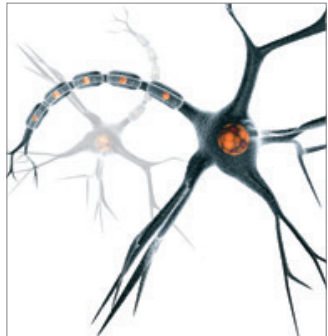

Neural Plasticity
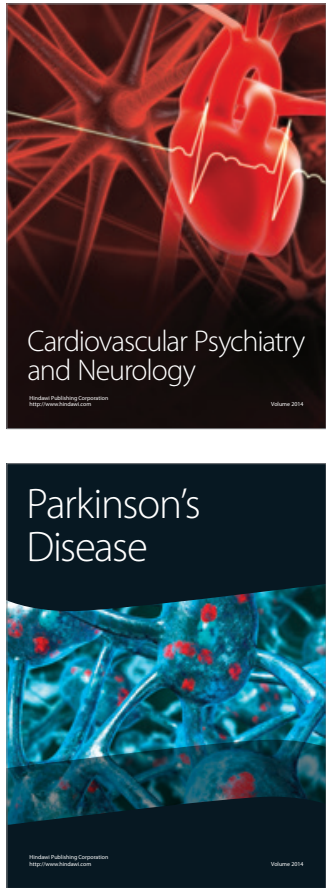